\title{
MODERN TECHNIQUES TO ANALYSES PRODUCTION DATA
}

\author{
Salma Akhter Iqbal ${ }^{a}$, Md. Zahidul Islam ${ }^{b}$ and Mohammad Shahedul Hossain ${ }^{b}$ \\ ${ }^{a}$ Department of Chemical Engineering and Polymer Science, Shahjalal University of Science and \\ Technology, Sylhet-3114 \\ ${ }^{b}$ Department of Petroleum \& Mining Engineering, Shahjalal University of Science and Technology \\ Sylhet-3114, Bangladesh
}

This paper shows a systematic \& comprehensive demonstration of the methods available for analyzing production data, highlighting the advantages and limitations of each method. These methods comprise those techniques developed by Arps $^{2}$, Fetkovich ${ }^{5}$, Blasingame ${ }^{2}$ and Agarwal-Gardner ${ }^{1}$ and a new method called Flowing Material Balance. Some methods yield recoverable reserves, while others give hydrocarbons-inplace. Traditional (Arps) decline analysis (exponential or hyperbolic) shows reasonable answers in many cases, but has its failings due to completely ignoring the flowing pressure data, one of the most important parameters. As a result, the reserves are underestimated or overestimated which are shown by tow examples.

\section{INTRODUCTION}

Over the past few years, techniques of production data analysis have advanced significantly. Many different methods are available now. However, there is no clear method that always yields the most reliable answer. The first systematic approach to analyzing oil and gas production data was presented by Arps in 1945. Simplicity makes the methodology the popular one. Being an empirical method, no knowledge of reservoir or well parameters is required.

Fetkovich (1980) was the first who exert the concept of using typecurves to analyses production data. The Fetkovich methodology uses the same Arps depletion bases to analyze boundary dominated flow and constant pressure typecurves for transient production.

Blasingame (1991) and Agarwal-Gardner (1998) also use typecurves for production data analysis. Using the flowing pressure data $\&$ production rates and they establish analytical solutions to calculate hydrocarbons-in-place and estimate expected recoverable reserves (EUR) dependently.

There are also modern analytical methods that do not use typecurves such as Flowing Material Balance. This technique estimates hydrocarbons- in-place using production rate and flowing pressure data from a reservoir under volumetric depletion.

\section{METHODOLOGY}

To maximize the benefits of each of the following methods, a systematic production data analysis is presented below:

1. Arps decline analysis (exponential, hyperbolic and harmonic)

2. Fetkovich typecurve analysis

3. Blasingame typecurve analysis

4. Agarwal-Gardner typecurve analysis

5. Normalized Pressure Integral (NPI) typecurves

6. Flowing Material Balance (new method)

\subsection{Data Preparation and Diagnostics}

1) Filter questionable data using Cartesian plot.

2) Calculate bottomhole flowing pressures

3) Estimate reservoir parameters:

- pi (bottomhole)

- Porosity, net pay, saturations

- Gas / fluids analysis

- PVT data (oil)

5) Determine the true cumulative values that are influenced by wellbore and use interpolation or extrapolation to calculate unknown flowing pressure. 


\section{TYPECURVE ANALYSIS}

The primary objective is to identify the dominant flow regime from the production data: Infinite Acting (radial flow, fracture linear flow, horizontal well flow), Transitional (influenced by boundaries) or Boundary Dominated (depletion or displacement). With boundary dominated flow, it is possible to predict ultimate reserves or fluids-inplace with confidence.

\subsection{Fetkovich}

Description

- Depletion analysis is empirical)

- Constant flowing pressure is assumed for Transient analysis

- Used for non-volumetric reservoirs

- Used for constant flowing pressures

Advantages

- No requirement of flowing pressure data

- Does not use pre-assumed dominant flow regime

- Empirical nature makes it versatile

Limitations

- Depletion analysis tends to be non-unique

- Only (EUR) is calculated with historical operating conditions

- Cannot differentiate the reservoir performance from production constraints

\subsection{Advanced Typecurve Methods}

Description

- Analytical depletion analysis

- Concepts of normalized rate, material balance time and pseudo time are used.

- Valid for single-phase volumetric reservoirs

Blasingame Typecurves

Advantages

- Rate-integral allows for a relatively smooth derivative typecurve which is not normally possible for drawdown data.

\section{Limitations}

- Rate-integral calculations are very sensitive to early- time errors.

- Rate-integral-derivative does not readily display the different flow regimes.

Agarwal-Gardner Rate-Time Typecurves

Advantages
- Inverse-pressure derivative typecurve has similar functionality to pressure transient derivative which distinguish flow regimes.

- The transition from infinite acting to boundary dominated flow occurs at a single vertical line, common to all typecurves on the plot.

Limitations

- Inverse-pressure derivative is usually too noisy to gain any meaningful interpretation.

- Overall, tends to be more non-unique than Blasingame.

NPI (Normalized Pressure Integral)

Description

- Analysis is the inverse of Agarwal-Gardner RateTime Typecurves.

\section{TYPECURVELESS ANALYSIS}

The non- typecurve methods are considered to be more suitable for quantitative analysis of reserves being Cartesian plots. The fluids-in-place analysis is performed once the presence of boundary dominated flow is confirmed from the diagnostics.

\subsection{Arps (Traditional Decline Analysis)}

Arps decline curve analysis follows directly from the diagnostics obtained using the Fetkovich typecurves.

Common Decline Analysis Concerns-

- Hyperbolic forecast limit the duration of the forecast should not be longer than 10 years.

- The historical flowing pressure trend should follow when forecast production. Steeply decline pressure trends will over-predict EUR

- Do not use "b" values that exceed 1 to determine EUR. Results will be likely unrealistic.

Advantages

- Easy and convenient to apply

- Does not require knowledge of pressure data or reservoir parameters

- Provides production forecast

Limitations

- Non unique, can often have large range of EURs depending on $b$ value used

- Cannot predict fluids-in-place without using empirical recovery factor method

- Cannot disassociate production conditions from reservoir analysis.

\subsection{Flowing Material Balance}


The Flowing Material Balance (FMB) is a recent production data analysis method, based on a modified version of the Agarwal-Gardner RateCumulative typecurves. The method is similar to a conventional material balance analysis but requires no shut-in pressure data.

Advantages

- Straight-forward and intuitive method

- Provides analytical fluids-in-place estimate without requiring shut-in pressures

- Linear scale data plotting makes the method superior to typecurve methods for estimating fluidsin-place.

Limitations

- Only applies to reservoirs in depletion (similar to $\mathrm{p} / \mathrm{z}$ plot)

\section{Examples}

The following two examples illustrate how modern methods give reliable answers than traditional.

\subsection{Example 1}

In this example, traditional (Arps) decline analysis underpredicts the recoverable-Gas-in-Place. The primary reason is that the well is flowing at a very low drawdown with increasing back pressure.

The well / reservoir parameters are as follows:

Initial pressure, $\mathrm{Pi}=1350 \mathrm{psia}$

Reservoir temperature, $\mathrm{T}_{\mathrm{R}}=120^{\circ} \mathrm{F}$

Pay zone thickness, $\mathrm{h}=20 \mathrm{ft}$

Gas gravity $=0.58$

Porosity, $\Phi=0.20$

Water saturation, $\mathrm{s}_{\mathrm{w}}=0.20$

Figure 1 shows the Blasingame, Agarwal-Gardner \& NPI typecurve and FMB plots for boundary dominated flow. After matching, these indicate that the gas initial in place (GIIP) is about $23.5 \mathrm{Bcf}$ with about 15.5 Bcf EUR. Figure 2 shows the Cartesian analysis plots where Traditional Exponential method shows the GIIP is only $4.7 \mathrm{Bcf}$ with approximately $3 \mathrm{Bcf}$ EUR.

\subsection{Example 2}

In this example, traditional (Arps) decline analysis overpredicts the recoverable-Gas-in-Place. The primary reason is that the well is flowing at a very low drawdown with increasing back pressure.

The well / reservoir parameters are as follows:

Initial pressure, $\mathrm{Pi}=1000$ psia

Reservoir temperature, $\mathrm{T}_{\mathrm{R}}=120^{\circ} \mathrm{F}$

Pay zone thickness, $\mathrm{h}=30 \mathrm{ft}$

Gas gravity $=0.65$

Porosity, $\Phi=0.30$
Water saturation, $\mathrm{s}_{\mathrm{w}}=0.20$

Figure 3 shows the Blasingame, Agarwal-Gardner \& NPI typecurve and FMB plots. It is observed that the well production is boundary dominated. After matching, these indicate that the GIIP is about 5.85 Bcf with about 3.2 Bcf EUR. Figure 4 shows the Cartesian analysis plots where Traditional Exponential method shows the GIIP is about $17 \mathrm{Bcf}$ with approximately 9 Bcf EUR.

\section{CONCLUSION}

A systematic approach to production data analysis that uses all the best methods available helps the analyst to visualize field performance. No single production data analysis method is capable of handling all types of data and reservoir types.

Traditional method shows inaccurate results with respect to modern methods that is not a good sign to measure field performance.

Modern methods provide a convenient and intuitive way to calculate fluids-in-place and EUR. These methods have better resolution for boundary dominated flow than Traditional method.

\section{REFERENCES}

1. Agarwal, R.G, Gardner, D.C, Kleinsteiber, S.W, and Fussell, D.D.: "Analyzing Well Production Data Using Combined Type Curve and Decline Curve Concepts," paper SPE 57916 presented at the 1998 SPE Annual Technical Conference and Exhibition, New Orleans, 27- 30 September.

2. Arps, J.J.: "Analysis of Decline Curves," Trans., AIME (1945), 160, 228

3. Blasingame, T.A, McCray, T.L, Lee, W.J: "Decline Curve Analysis for Variable Pressure Drop/Variable Flowrate Systems," paper SPE 21513 presented at the SPE Gas Technology Symposium, 23-24 January, 1991

4. Blasingame, T.A., Johnston, J.L., Lee, W.J.: "Type-Curve Analysis Using the Pressure Integral Method," paper SPE 18799 presented at the SPE California Regional Meeting held in Bakersfield, April 5-7, 1989.

5. Fetkovich, M.J.: "Decline Curve Analysis using Type Curves," JPT (June 1980), 1065. 
Fig. 2: Traditional Exponential Plot for Example 1
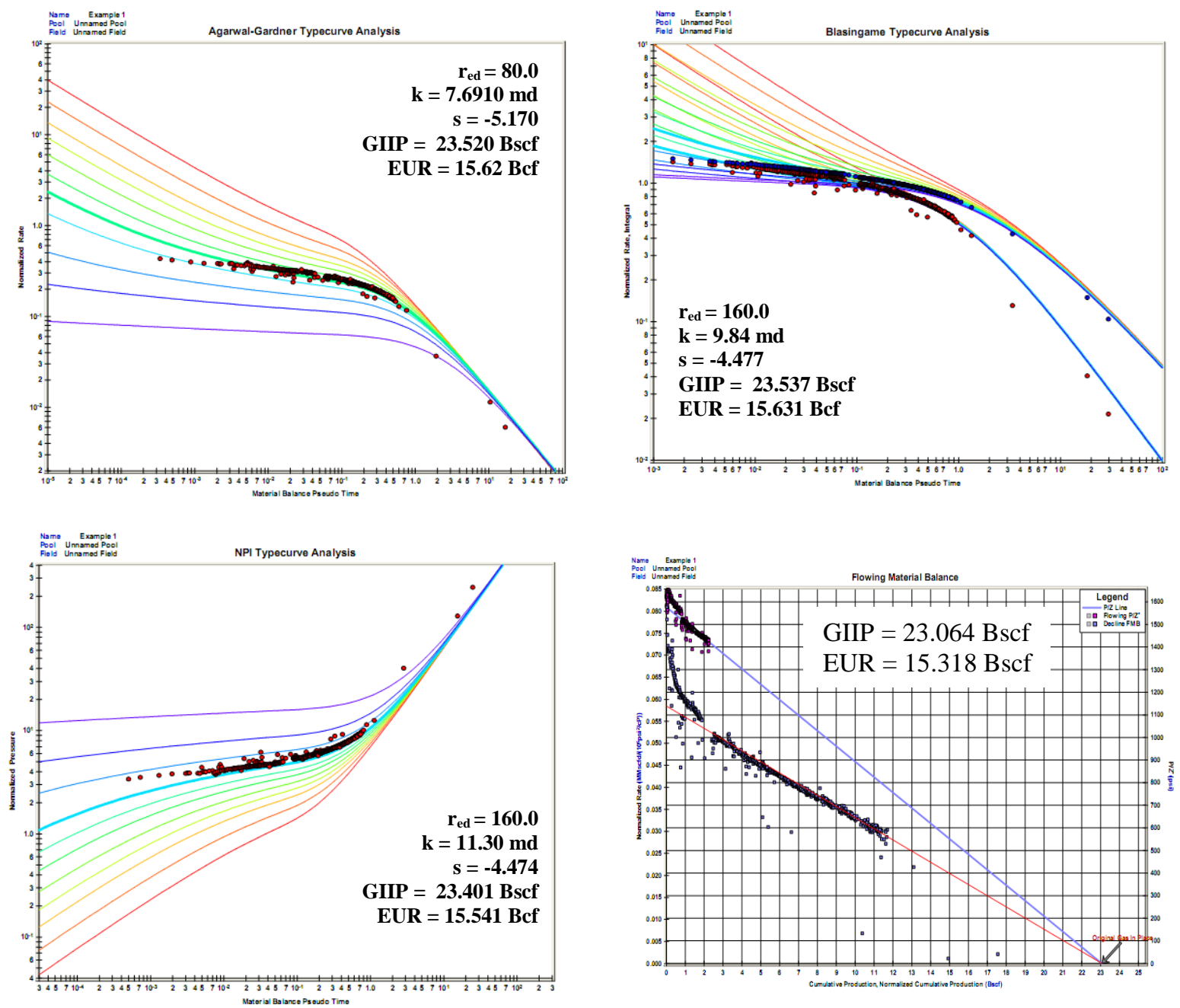

Fig. 1: Agarwal-Gardner, Blasingame \& NPI typecurve and FMB Plots for Example 1

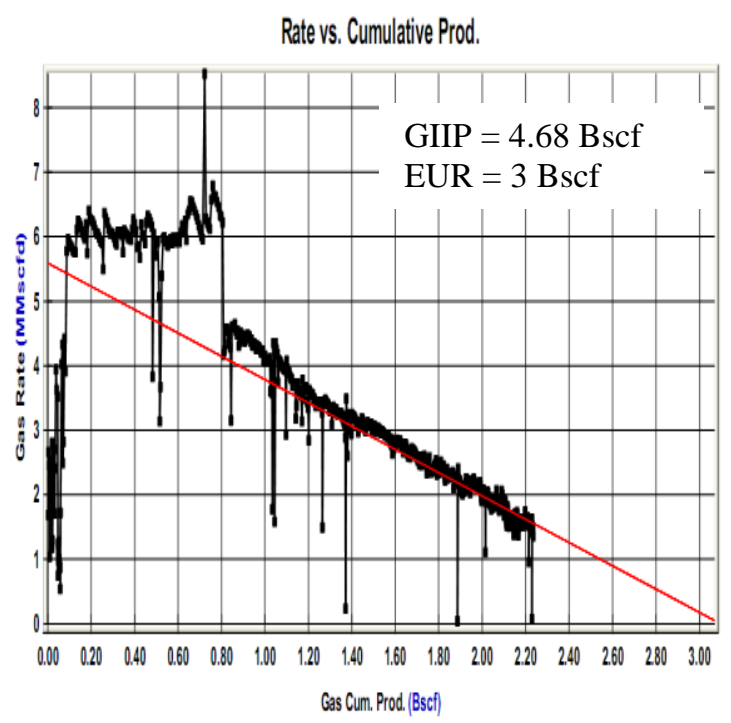


Fig. 4: Traditional Exponential Plot for Example 2
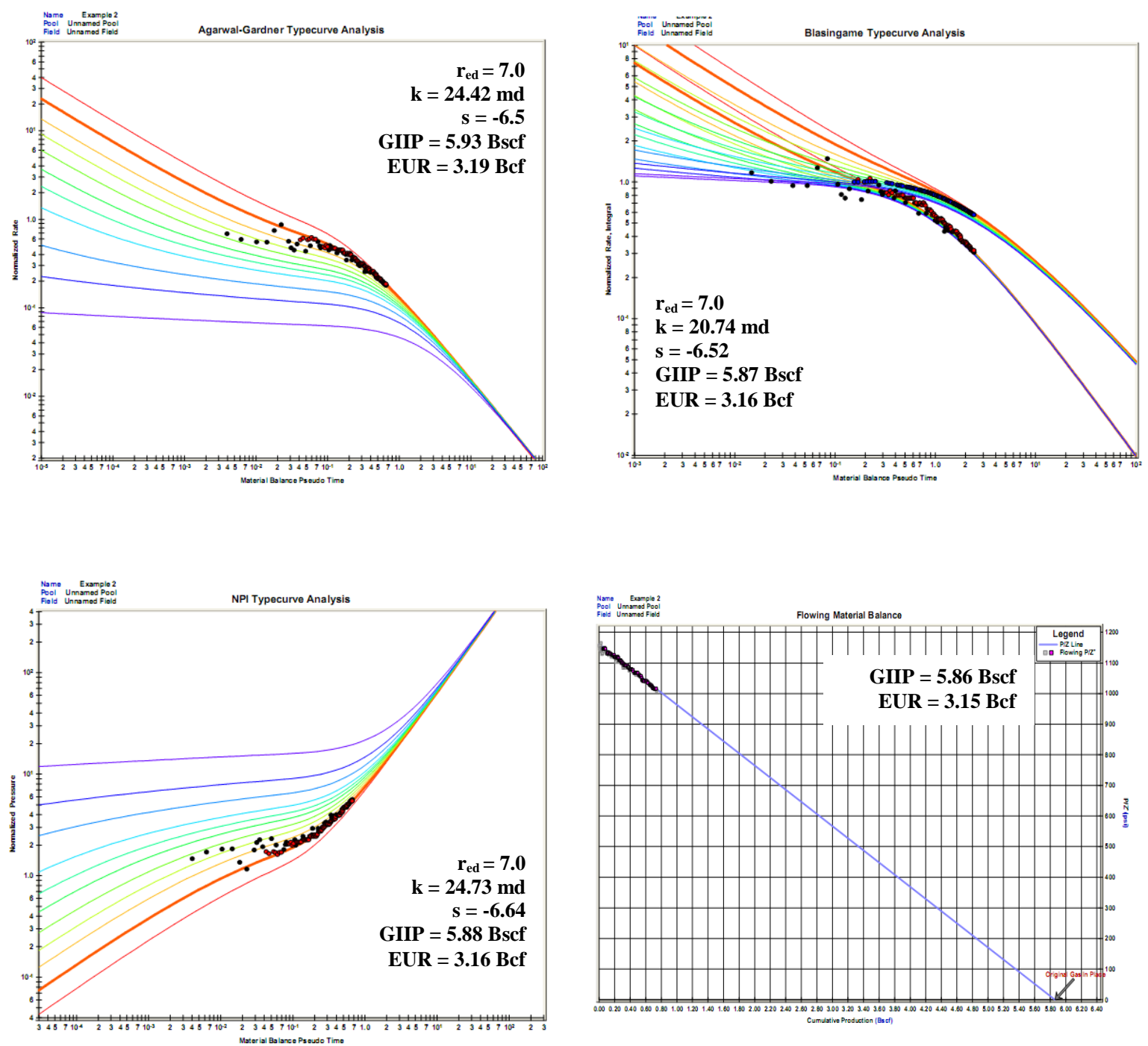

Fig. 3: Agarwal-Gardner, Blasingame \& NPI typecurve and FMB Plots for Example 2

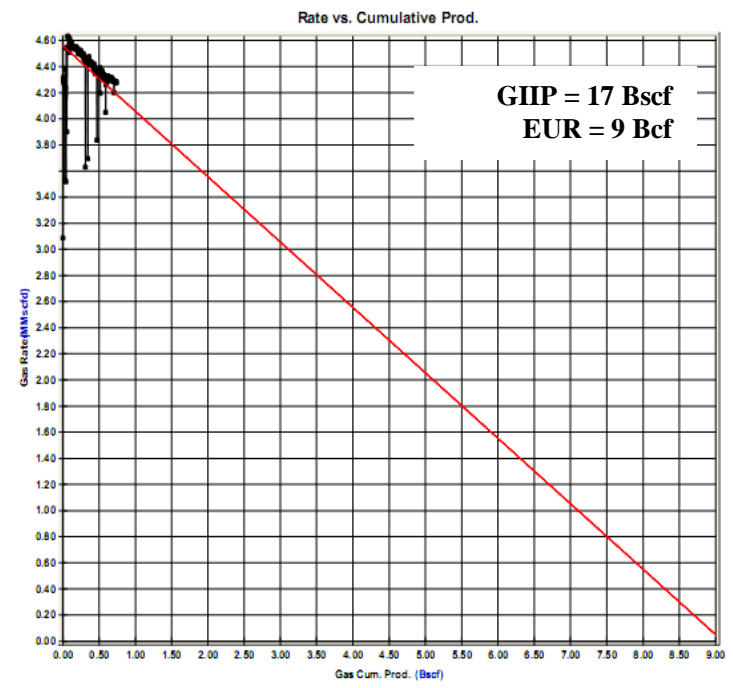

